\title{
Abdominal Problems in Children with Congenital Cardiovascular Abnormalities
}

\author{
Lütfi Hakan Güney ${ }^{1}$, Coşkun Araz ${ }^{2}$, Deniz Sarp Beyazpınar ${ }^{3}$, İfan Serdar Arda ${ }^{1}$, Esra Elif Arslan ${ }^{1}$, \\ Akgün Hiçsönmez ${ }^{1}$
}

\footnotetext{
'Department of Pediatric Surgery, Başkent University Faculty of Medicine, Ankara, Turkey

${ }^{2}$ Department of Anesthesiology, Başkent University Faculty of Medicine, Ankara, Turkey

${ }^{3}$ Department of Cardiovasculer Surgery, Başkent University Faculty of Medicine, Ankara, Turkey
}

Background: Congenital cardiovascular abnormality is an important cause of morbidity and mortality in childhood. Both the type of congenital cardiovascular abnormality and cardiopulmonary bypass are responsible for gastrointestinal system problems.

Aims: Intra-abdominal problems, such as paralytic ileus, necrotizing enterocolitis, and intestinal perforation, are common in patients who have been operated or who are being followed for congenital cardiovascular abnormalities. Besides the primary congenital cardiovascular abnormalities, ischemia secondary to cardiac catheterization or surgery contributes to the incidence of these problems.

Study Design: Cross-sectional study.

Methods: In this study, we aimed to screen the intraabdominal problems seen in patients with congenital cardiovascular abnormalities who had undergone surgical or angiographical intervention(s). Patients with congenital cardiovascular abnormalities who had been treated medically or surgically between 2000 and 2014 were analyzed retrospectively in terms of intra-abdominal problems. The patients' demographic data, type of congenital cardiovascular abnormalities, the intervention applied (surgical, angiographic), the incidence of intra-abdominal problem(s), the interventions applied for the intra-abdominal problems, and the results were evaluated.

Results: Fourteen (Group I) of the 76 patients with congenital cardiovascular abnormalities diagnosis were operated due to intra-abdominal problems, and 62 (Group II) were followed-up clinically for intra-abdominal problems. In Group I (10 boys and 4 girls), 11 patients were aged between 0 and 12 months, and three patients were older than 12 months. Group II included 52 patients aged between 0 and 12 months and 10 patients older than 12 months. Cardiovascular surgical interventions had been applied to six patients in Group I and 40 patients in Group II. The most frequent intraabdominal problems were necrotizing enterocolitis and intestinal perforation in Group I, and paralytic ileus in Group II. Seven of the Group I patients and 22 of the Group II patients died. The patients who died in both groups had more than three congenital cardiovascular abnormalities in the same patient, and $80 \%$ of these patients had been operated for congenital cardiovascular abnormalities.

Conclusion: The gastrointestinal system is involved in important complications experienced by patients with congenital cardiovascular abnormalities. The mortality rate was higher in operated patients due to gastrointestinal complications. Gastrointestinal complications are more frequent in patients with cyanotic anomalies. The presence of more than one congenital cardiovascular abnormality in a patient increased the mortality rate. Keywords: Abdominal surgery, cardiopulmonary, congenital, cardiovascular abnormalities, intestinal ischemia 
Congenital cardiovascular abnormality is an important cause of morbidity and mortality in childhood (1). Gastrointestinal system problems are not rare in patients with Congenital cardiovascular abnormalities $(2,3)$. Both the type of congenital cardiovascular abnormality and cardiopulmonary bypass are responsible for gastrointestinal system complications. Heart failure, hypotension, and cardiopulmonary bypass-related hypoperfusion may cause a short- or long-term ischemia in the gastrointestinal system. The tissue injury caused by ischemia may lead to complications ranging from a decrease in intestinal motility to necrosis. In this study, gastrointestinal system problems of patients with congenital cardiovascular abnormalities were investigated regarding predetermined parameters.

\section{MATERIALS AND METHODS}

In this study, gastrointestinal system problems of children with congenital cardiovascular abnormalities who underwent surgical intervention and/or cardiac catheterization at a tertiary health care institution between 2000 and 2014 were retrospectively reviewed. All procedures were performed by the same team. All patients received a detailed explanation of the procedure before surgery, and the study was approved by the hospital review board.

After our project had been approved by Başkent Universty Ethical committee. Medical records of the children who had been treated by the Department of Pediatric Surgery were studied. The parameters considered were: age, gender, type of congenital cardiovascular abnormality, interventions performed for congenital cardiovascular abnormality, gastrointestinal complications, and follow-up findings. The results obtained were compared with the findings in the literature.

After the patients with congenital cardiovascular abnormalities were diagnosed to have surgical gastrointestinal system problems, a proper informed consent was taken from their parents and they were transferred to the anesthesia room, and continuous arterial pressure and electrocardiographic monitoring were established before induction of anesthesia by the administration of $1-2 \mu \mathrm{gr} / \mathrm{kg}$ of fentanyl citrate (Fentanyl, Meditera Medical Istanbul, Turkey) delivered intravenously and a titrated dose of Thiopental sodium (PENTAL $®$ Sodyum, I.E. Ulagay, İstanbul, Turkey) $(5-7 \mathrm{mg} / \mathrm{kg})$. Muscle paralysis was accomplished with vecuronium (Norcurone, $\mathrm{N}$ V Organon, the Netherland) $(0.1 \mathrm{mg} / \mathrm{kg})$. After the induction of anesthesia, a central venous access was created. All patients received antibiotic prophylaxis consisting of cefuroxime sodium (Zinnat, Glaxo Smith Kline Medical, London, England) (30 $\mathrm{mg} / \mathrm{kg}$ every 8 hours for 24 hours) together with prophylactic $\mathrm{H}_{2}$-receptor blockade using ranitidine (Ulcuran, Abfar Medical, İstanbul, Turkey), with a dose of $50 \mathrm{mg}$ that was intravenously administered at the time of anesthesia induction. We administered positive pressure ventilation with air and oxygen (60:40) with a variable inspiratory concentration of sevoflurane (Sevorane ${ }^{\circledR}$, Queenborough, England) (0.5-1\%).

\section{Statistical analysis}

Descriptive statistics are showed as mean \pm standard deviation or median $(75 \%)$ for continuous variables. The $t$ test was performed for normally distributed variables, and the Mann-Whitney U test was performed for variables that did not distribute normally. The continuity correction Chi-square test was used for categoric variables, and results are shown as the frequency and percentage (\%). A p-value below 0.05 was accepted as significant.

Logistic regression analysis was performed to find risk factors. IBM SPSS Statistics for Windows, Version 20.0 (Armonk, NY, USA) was used for statistical analysis.

\section{RESULTS}

A total of 3373 patients with congenital cardiovascular abnormality had undergone surgical intervention and/or cardiac catheterization. Gastrointestinal complications were recorded in $76(2.3 \%)$ of the total number, $14(18.5 \%)$ of whom were operated (Group I), while 62 patients $(81.5 \%)$ were treated non-surgically (Group II).

The demographic data of the patients are presented in Table 1. In Group I (10 boys and 4 girls), 11 patients were aged between 0 and 12 months, and three patients were older than 12 months. Group II included 52 patients aged between 0 and 12 months, and 10 patients older than 12 months.

TABLE 1. Distribution of patients according to age and gender

\begin{tabular}{|c|c|c|c|c|c|c|c|c|c|c|c|c|}
\hline \multirow{3}{*}{$\begin{array}{l}\text { Age } \\
\text { Gender }\end{array}$} & \multicolumn{5}{|c|}{ Group I } & \multicolumn{7}{|c|}{ Group II } \\
\hline & \multicolumn{2}{|c|}{$0-12$ months } & \multicolumn{2}{|c|}{$>12$ months } & \multicolumn{2}{|c|}{ TOTAL } & \multicolumn{2}{|c|}{$0-12$ months } & \multicolumn{2}{|c|}{$>12$ months } & \multicolumn{2}{|c|}{ TOTAL } \\
\hline & Male & Female & Male & Female & Male & Female & Male & Female & Male & Female & Male & Female \\
\hline & 8 & 3 & 2 & 1 & 10 & 4 & 35 & 17 & 6 & 4 & 41 & 21 \\
\hline TOTAL & \multicolumn{2}{|c|}{11} & \multicolumn{2}{|c|}{3} & \multicolumn{2}{|c|}{14} & \multicolumn{2}{|c|}{52} & \multicolumn{2}{|c|}{10} & \multicolumn{2}{|c|}{62} \\
\hline
\end{tabular}

Group I: operated patients; Group II: medically managed patients 
Congenital cardiovascular abnormalities of the patients include: ventricular septal defect, atrial septal defect, ductus arteriosus defect, pulmonar stenosis, double outlet right ventricle, transposition of the great arteries, aortic coarctation, fallot tetralogy, and tricuspid atresia.

Eleven (78.5\%) of the 14 patients in Group I had cyanotic congenital cardiovascular abnormalities, and $3(21.5 \%)$ had acyanotic congenital cardiovascular abnormalities, while 44 (71\%) of the 62 patients in Group II had cyanotic and 18 (29\%) had acyanotic congenital cardiovascular abnormalities.

The interventions performed for the diagnosis or treatment of congenital cardiovascular abnormalities are listed in Table 2.

The patients who underwent cardiac operations were divided into two groups: cyanotic and acyanotic. Cardiopulmonary bypass and aortic cross-clamp times were significantly longer in patients who underwent surgical correction for cyanotic congenital malformations ( $\mathrm{p}=0.0017$ and 0.023 , respectively; Table 3).

Although some of the complications that occurred due to the surgeries and surgical interventions in Group I were not directly related to the gastrointestinal system, they were included in the study because laparotomy was performed in order to treat them. For example, retroperitoneal hematoma secondary to femoral catheterization was drained via laparotomy, and liver laceration occurred during pericardiosynthesis that was performed for pericardial tamponade and was repaired via laparotomy. Two patients with free air in the abdominal underwent explorative laparotomy, but no perforation was detected. Peritoneal opening during mediastinal tube insertion during cardiac surgery was thought to be the reason for the free air in the abdomen in these patients.

In Group I, necrotizing enterocolitis, a serious gastrointestinal system complication, developed in 10 patients. All these patients had cyanotic congenital cardiovascular abnormalities

TABLE 2. Distribution of interventions performed according to the groups

\begin{tabular}{lcc}
\hline Investigation performed & Group I & Group II \\
\hline Cardiac catheterization & $8(57.1 \%)$ & $22(35.5 \%)$ \\
Surgery & $6(42.9 \%)$ & $40(64.5 \%)$ \\
TOTAL & 14 & 62 \\
\hline
\end{tabular}

Group I: operated patients; Group II: medically managed patients

TABLE 3. Cardiopulmonary bypass and aortic cross-clamp times in cyanotic and acyanotic patients

\begin{tabular}{lccc}
\hline & Acyanotic & Cyanotic & p value \\
\hline Patients & 21 & 55 & \\
$\begin{array}{l}\text { Aortic cross-clamp } \\
\text { (median value) }\end{array}$ & 46 minutes & 99 minutes & 0.0017 \\
$\begin{array}{l}\text { Cardiopulmonary bypass } \\
\text { (median value) }\end{array}$ & 31 minutes & 91 minutes & 0.023
\end{tabular}

(Table 4). Visualization of free air in abdominal plain radiograph, intestinal content detection in parasynthesis following extensive dense-liquid detection in abdominal ultrasonography, and edema and color change in the abdominal wall were accepted as laparotomy indications. In these patients, localized or wide necrosis and single or multiple foci of perforation were detected. In two cases abdominal exploration revealed no abnormality, whereas primary repair of intestinal perforation was performed in two patients and ileostomy or colostomy was performed in ten patients.

In Group II, gastrointestinal complications were approximately three times more frequent in patients with cyanotic congenital cardiovascular abnormalities than in patients with acyanotic congenital cardiovascular abnormalities (Table 5).

The patients with abdominal distention, bilious vomiting, bilious nasogastric drainage, jejuno-ileal air-fluid levels on erect plain abdominal radiograms, and immotile bowel on sonography were diagnosed as paralytic ileus. In these patients, oral feeding was stopped, nasogastric decompression was performed, triple-antibiotic therapy (ceftriaxone (Rocephin, Roche Medical, Basel, Switzerland) $50 \mathrm{mg} / \mathrm{kg} /$ day or ampicillin/sulbactam (Sulcid, İ.E. Ulagay Medical, İstanbul, Turkey) $50 \mathrm{mg} / \mathrm{kg} /$ day, amikacin (Amiketem, İ.E. Ulagay Medical, İstanbul, Turkey) $15 \mathrm{mg} / \mathrm{kg} /$ day, and ornidazole (Biteral, Roche Medical, Basel, Switzerland) $20 \mathrm{mg} / \mathrm{kg} /$ day) was started, and the patient was followed by plain abdominal radiograms taken every 12-24 hours. Follow-up and medication was ended after gaining intestinal motility with spontaneous gas and stool passage.

Stage I and II necrotizing enterocolitis was defined by deterioration of the patient's status, occult or massive blood detection in the stool, abdominal distention, and bilious vomit-

TABLE 4. Distribution of the indications of abdominal operations in Group I (operated patients), according to the presence of cyanosis

\begin{tabular}{lccc}
\hline & Acyanotic & Cyanotic & TOTAL \\
\hline Necrotizing enterocolitis (Stage III) & - & 10 & $10(71.4 \%)$ \\
Retroperitoneal hematoma & 1 & - & $1(7.2 \%)$ \\
Intra-abdominal free air & 1 & 1 & $2(14.2 \%)$ \\
Liver laceration & 1 & - & $1(7.2 \%)$ \\
TOTAL & 3 & 11 & 14
\end{tabular}

TABLE 5. Complications developed in Group II (Medically managed patients)

\begin{tabular}{lccc}
\hline & Acyanotic & Cyanotic & TOTAL \\
\hline Paralytic ileus & 12 & 30 & $42(67.7 \%)$ \\
$\begin{array}{l}\text { Necrotizing enterocolitis } \\
\text { (Stage I-II) }\end{array}$ & 6 & 13 & $19(30.6 \%)$ \\
Ogilvie syndrome & - & 1 & $1(1.7 \%)$ \\
TOTAL & 18 & 44 & 62
\end{tabular}


ing. Oral feeding was stopped and nasogastric decompression was performed, triple-antibiotic therapy (ceftriaxone $50 \mathrm{mg}$ / $\mathrm{kg} /$ day or ampicillin/sulbactam $50 \mathrm{mg} / \mathrm{kg} /$ day, amikacin 15 $\mathrm{mg} / \mathrm{kg} / \mathrm{day}$, and omidazole $20 \mathrm{mg} / \mathrm{kg} / \mathrm{day}$ ) was started and the patient was followed-up by plain abdominal radiographs every $8-12$ hours. Parenteral nutrition was started if oral feeding could not be provided for at least 3 days. Medication was ended upon improvement in X-ray findings and bowel motility with stool and gas passage.

In the case with Ogilvie Syndrome, severe abdominal distention was seen and colonic expansion was detected on plain abdominal X-ray. Similarly, oral feeding was stopped and nasogastric decompression was performed, triple-antibiotic therapy (ceftriaxone $50 \mathrm{mg} / \mathrm{kg} /$ day or ampicillin/sulbactam $50 \mathrm{mg} / \mathrm{kg} / \mathrm{day}$, amikacin $15 \mathrm{mg} / \mathrm{kg} /$ day, and ornidazole $20 \mathrm{mg} /$ $\mathrm{kg}$ /day) was started, the colon was decompressed via a rectal tube, rectal stimulation, or enema. Treatment was ended after distention disappeared with neostigmine (Neostigmine, Adeka Medical, Samsun, Turkey) infusion ( $2 \mathrm{mg} / \mathrm{kg} /$ day).

Seven patients in Group I (50\%) and 22 patients (35.5\%) in Group II died. The distribution of these patients according to the type of congenital cardiovascular abnormality is given in Table 6.

The mortality rates of the two groups were compared, and no statistically significant difference was found $(\mathrm{p}=0.458)$.

All the patients who died in Group I had cyanotic-type congenital cardiovascular abnormalities. Five $(23 \%)$ of the 22 patients who died in Group II had acyanotic congenital cardiovascular abnormalities and 17 (77\%) patients had cyanotic abnormalities. In both groups, the survival rates in cyanotic and acyanotic patients were not significantly different $(p=0.361)$. In the overall evaluation of the study group, 5 $(23.8 \%)$ of the 21 acyanotic patients and 24 (43.6\%) of the 55 cyanotic patients died. No statistically significant difference was found between the cyanotic and acyanotic patients with regard to survival rates $(\mathrm{p}=0.122)$.

Sixty-six patients had three or more congenital cardiovascular abnormalities. In both groups, the number of congenital cardiovascular abnormalities in patients who died was at least three.

TABLE 6. Distribution of the patients who died according to the type of congenital cardiovascular abnormality

\begin{tabular}{lcccc}
\hline & \multicolumn{2}{c}{ Group I } & \multicolumn{2}{c}{ Group II } \\
& Acyanotic & Cyanotic & Acyanotic & Cyanotic \\
\hline Survivors & 3 & 4 & 13 & 27 \\
Exitus & 0 & 7 & 5 & 17 \\
TOTAL & 3 & 11 & 18 & 44 \\
& & & & \multicolumn{2}{c}{62} \\
\hline
\end{tabular}

Group I: operated patients; Group II: medically managed patients

\section{DISCUSSION}

Gastrointestinal ischemia can cause variable degrees of tissue injury. Ischemia disturbs tissue integrity via mediators appearing in the affected organ depending on the length of the period of exposure. The result can be either temporary, like paralytic ileus, or permanent, like necrosis. We observed that the gastrointestinal system complications were not uncommon in children who were operated for congenital cardiovascular abnormalities. Although congenital cardiovascular abnormalities are a well-known factor for necrotizing enterocolitis development, there is no satisfying data in the literature about its incidence, pathophysiology, and effects (1-6). In our study, gastrointestinal system complications were detected in 76 congenital cardiovascular abnormalities patients. In the 14year period, the number of patients who underwent a surgical intervention because of congenital cardiovascular abnormalities in our hospital was 3373. The rate of gastrointestinal system complications was $2.3 \%$, which is similar to the previously reported rates $(1,7)$.

Necrotizing enterocolitis, a problem with high mortality, is characterized by translocation of pathogenic enteric bacteria out of the intestinal wall (8-12). Necrotizing enterocolitis is generally seen in newborns, and it constitutes the most important reason for emergent surgery at this age. Intestinal ischemia has an important role in its etiology. One of the theories suggested for the physiopathology of ischemia causing necrotizing enterocolitis is the "diving reflex" (12-14). According to this theory, in the case of a general ischemia, in order to maintain oxygenation of more vital organs, more blood flow is temporarily directed from the splanchnic area to the vital organs, and the result is ischemia in the intestinal wall. A similar situation may occur in patients undergoing surgery for congenital cardiovascular abnormalities. Hypotension during cardiopulmonary bypass or a delay in starting the cardiac functions after ending the pump function may cause ischemia in the splanchnic area via trigger of the "diving reflex". This explains the frequency of intestinal complications in patients with congenital cardiovascular abnormalities. Cheng et al. (3) reported that among the symptomatic newborns with congenital cardiovascular abnormalities, diagnosed as necrotizing enterocolitis, the mortality rate in the cyanotic ones $(71 \%)$ was apparently higher than the acyanotic ones (39\%). They also emphasized that those necrotizing enterocolitis cases with congenital cardiovascular abnormalities had higher birth weights and APGAR (activity and muscle tone, pulse, grimace response, appearance, respiration) scores than the necrotizing enterocolitis cases with no congenital cardiovascular abnormalities.

In this study, necrotizing enterocolitis developed in 10 (71.4\%) of 14 patients who underwent surgery for gastrointes- 
tinal system complications, and in $19(30.6 \%)$ of 62 patients who received medical therapy. Eleven $(78.5 \%)$ of the 14 patients in Group I and 44 (71\%) of the 62 patients in Group II had cyanotic-type congenital cardiovascular abnormalities. According to our results, the probability of necrotizing enterocolitis is higher in cyanotic patients, which supports the literature data.

In this study, in 42 (67.7\%) of the 62 patients in Group II, paralytic ileus was detected. When the total 76 patients are considered, this rate was $55.2 \%$. Simić et al. (15) reported that paralytic ileus constitutes $36 \%$ of the gastrointestinal complications, and so our results are compatible with those in the literature. Twelve (28.5\%) of the 42 patients with paralytic ileus had acyanotic-type congenital cardiovascular abnormalities, and 30 (71.5\%) of them had cyanotic-type abnormalities.

Both necrotizing enterocolitis and slowed or diminished intestinal motility were more frequently seen in cyanotic congenital cardiovascular abnormalities patients than in acyanotic congenital cardiovascular abnormalities patients. According to the literature, there are two main reasons for this: 1) Cyanotic abnormality directly causes hypoperfusion in the gastrointestinal system, and therefore, causes ischemic complications (16-21);2) Hypotension and ischemia related to cardiopulmonary bypass, in addition to reperfusion injury, which develops after surgical correction, can cause tissue damage in the gastrointestinal system (1,22-24).

Another clinically proven complication of cardiopulmonary bypass is an increase in intestinal wall permeability (25-27), while another reason for tissue damage after cardiopulmonary bypass is systemic inflammatory response syndrome (28-30). An increase in intestinal permeability due to any reason is one of the important factors in necrotizing enterocolitis pathogenesis. We think that all the reasons mentioned above may have taken a role in the etiology of the gastrointestinal system complications encountered in our patients.

Despite identification of the risk factors, the nature of the gastrointestinal complications varies and the precise etiology is unclear. They may arise de novo or due to preexisting gastrointestinal disorders, visceral hypoperfusion, and free radical-mediated reperfusion injury. Another important factor may be the use of cardiopulmonary bypass using non-pulsatile flow, which is associated with the development of a gastric mucosal acidosis and may have implications for the development of postoperative complications.

One parameter in our study was different from the literature data: the number of coexisting congenital cardiovascular abnormalities per patient. According to our results, the patients with gastrointestinal system complications in both groups had at least three abnormalities, and thus the number of coexistent congenital cardiovascular abnormalities of a newborn is di- rectly proportional to the risk of gastrointestinal system complications. It is also a negative prognostic indicator. Twentyone patients had non-complex cardiac anomaly (ASD; Atrial septal defect, PDA; Patent ductus arteriosus), and the rest had complex cardiac malformation. The distribution of the patients according to the type of cardiac vascular abnormalities is summarized in Tables 3 and 6.

Gastrointestinal system complications are not uncommon in patients with congenital cardiovascular abnormalities. Although it was not statistically significant in our study, mortality was higher in patients who underwent laparotomy for gastrointestinal system complications than in patients who were medically managed. Gastrointestinal system complication and mortality rates were higher in cyanotic congenital cardiovascular abnormalities patients than in the patients who had acyanotic congenital cardiovascular abnormalities. Furthermore, cardiopulmonary bypass and aortic clamping times were significantly prolonged in patients who developed gastrointestinal complications. A number of predictive factors contribute to the development of gastrointestinal complications after cardiopulmonary bypass surgery. Knowledge of these factors may lead to earlier identification of patients at increased risk, and may allow more efficient and earlier interventions to reduce mortality. In centers where congenital cardiovascular abnormalities surgery is performed, a multidisciplinary approach and cooperation with pediatric surgeons contribute to early and appropriate detection and treatment of gastrointestinal complications.

Ethics Committee Approval: Ethics committee approval was received for this study from the ethics committee of Baskent University Ethical Committee (KA15/49).

\section{Informed Consent: N/A.}

Peer-review: Externally peer-reviewed.

Author contributions: Concept - İ.S.A.; Design - D.S.B., L.H.G.; Supervision - A.H.; Resource - C.A.; Materials - E.E.A.; Data Collection \&/or Processing - L.H.G.; Analysis \&/or Interpretation - L.H.G., E.E.A.; Literature Search - İ.S.A, L.H.G.; Writing - L.H.G.; Critical Reviews - A.H., İ.S.A.

Acknowledgements: The authors thank Dr. Erkin Sönmez for assistance.

Conflict of Interest: No conflict of interest was declared by the authors.

Financial Disclosure: The authors declared that this study has received no financial support. 


\section{REFERENCES}

1. McElhinney DB, Hedrick HL, Bush DM, Pereira GR, Stafford PW, Gaynor JW, et al. Necrotizing enterocolitis in neonates with congenital heart disease: risk factors and outcomes. Pediatrics 2000;106:1080-7. [CrossRef]

2. Fatica C, Gordon S, Mossad E, McHugh M, Mee R. A cluster of necrotizing enterocolitis in term infants undergoing open heart surgery. Am J Infect Control 2000;28:130-2. [CrossRef]

3. Cheng W, Leung MP, Tam PK. Surgical intervention in necrotizing enterocolitis in neonates with symptomatic congenital heart disease. Pediatr Surg Int 1999;15:492-5. [CrossRef]

4. Rand T, Weninger M, Kohlhauser C, Bischof S, Heinz-Peer G, Trattnig S, et al. Effects of umbilical arterial catheterization on mesenteric hemodynamics. Pediatr Radiol 1996;26:435-8. [CrossRef]

5. Pumberger W, Mayr M, Kohlhauser C, Weninger M. Spontaneous localized intestinal perforation in very-low-birth-weight infants: a distinct clinical entity different from necrotizing enterocolitis. J Am Coll Surg 2002;195:796-803. [CrossRef]

6. Nankervis C, Giannone P, Reber K. The Neonatal Intestinal Vasculature: Contributing Factors to Necrotizing Enterocolitis. Semin Perinatol 2008;32:83-91. [CrossRef]

7. Kumle B, Boldt J, Suttner SW, Piper SN, Lehmann A, Blome M, et al. Influence of prolonged cardiopulmonary bypass times on splanchnic perfusion and markers of splanchnic organ function. Ann Thorac Surg 2003;75:1558-64. [CrossRef]

8. Maayan-Metzger A, Itzchak A, Mazkereth R, Kuint J. Necrotizing enterocolitis in full-term infants: case-control study and review of the literature. J Perinatol 2004;24:494-9. [CrossRef]

9. Reber KM, Nankervis CA, Nowicki PT. Newborn intestinal circulation. Physiology and pathophysiology. Clin Perinatol 2002;29:23-39. [CrossRef]

10. Powell RW, Dyess DL, Collins JN, Roberts WS, Tacchi EJ, Swafford AN Jr, et al. Regional blood flow response to hypothermia in premature, newborn, and neonatal piglets. $J$ Pediatr Surg 1999;34:193-8. [CrossRef]

11. Albanese CT, Rowe MI. Necrotizing enterocolitis. In: O’Neill JA, Jr (ed.), Pediatric Surgery 5th ed; Volume 2. St. Louis, Missouri, 1998, pp. 1297-320.

12. Sweet DG, Craig B, Halliday HL, Mulholland C. Gastro-intestinal complications following neonatal cardiac catheterisation. $J$ Perinat Med 1998;26:196-200. [CrossRef]

13. Bolisetty S, Lui K, Oei J, Wojtulewicz J. A regional study of underlying congenital diseases in term neonates with necrotizing enterocolitis. Acta Paediatr 2000;89:1226-30. [CrossRef]

14. Cozzi C, Aldrink J, Nicol K, Nicholson L, Cua C. Intestinal location of necrotizing enterocolitis among infants with congenital heart disease. J Perinatol 2013;33:783-5. [CrossRef]

15. Simić O, Strathausen S, Hess W, Ostermeyer J. Incidence and prognosis of abdominal complications after cardiopulmonary bypass. Cardiovasc Surg 1999;7:419-24. [CrossRef]

16. Tao W, Zwischenberger JB, Nguyen TT, Vertrees RA, McDaniel LB, Nutt LK, et al. Gut mucosal ischemia during normother- mic cardiopulmonary bypass results from blood flow redistribution and increased oxygen demand. J Thorac Cardiovasc Surg 1995;110:819-28. [CrossRef]

17. Mangi AA, Christison-Lagay ER, Torchiana DF, Warshaw AL, Berger DL. Gastrointestinal complications in patients undergoing heart operation: an analysis of 8709 consecutive cardiac surgical patients. Ann Surg 2005;241:895-901; discussion 901-4. [CrossRef]

18. Gasz B, Lenard L, Racz B, , Benko L, Borsiczky B, Cserepes $\mathrm{B}$, et al. Effect of cardiopulmonary bypass on cytokine network and myocardial cytokine production. Clin Cardiol 2006;29:3115. [CrossRef]

19. Rothwell-Jackson RL. Idiopatic large bowel obstruction. $\mathrm{Br} J$ Surg 1963;50:797. [CrossRef]

20. Narkevis CA, Giannone PJ, Reber KM. The Neonatal Intestinal Vasculature Contributing Factors to Necrotizing Enterocolitis. Semin Perinatol 2008;32:83-91. [CrossRef]

21. Young $\mathrm{C}$, Kingma S, Neu J. Ischemia-Reperfusion and Neonatal Intestinal Injury. J Pediatr 2011;158:25-8. [CrossRef]

22. Allen BS. The clinical significance of the reoxygenation injury in pediatric heart surgery. Semin Thorac Cardiovasc Surg Pediatr Card Surg Annu 2003;6:116-27. [CrossRef]

23. Hebra A, Brown MF, Hirschl RB, McGeehin K, O’Neill JA Jr, Norwood WI, et al. Mesenteric ischemia in hypoplastic left heart syndrome. J Pediatr Surg 1993;28:606-11. [CrossRef]

24. Curzon CL, Milford-Beland S, Li JS, O'Brien SM, Jacobs JP, Jacobs ML, et al. Cardiac surgery in infants with low birth weight is associated with increased mortality: analysis of the Society of Thoracic Surgeons Congenital Heart Database. J Thorac Cardiovasc Surg 2008;135:546-51. [CrossRef]

25. Malagon I, Onkenhout W, Klok G, van der Poel PF, Bovill JG, Hazekamp MG. Gut permeability in paediatric cardiac surgery. Br J Anaesth 2005;94:181-5. [CrossRef]

26. Braun JP, Schroeder T, Buehner S, Dohmen P, Moshirzadeh M, Grosse J, et al. Splanchnic oxygen transport, hepatic function and gastrointestinal barrier after normothermic cardiopulmonary bypass. Acta Anaesthesiol Scand 2004;48:697-703. [CrossRef]

27. Hashemzadeh K., Hashemzadeh S. Predictors and outcome of gastrointestinal complications after cardiac surgery. Minerva Chir 2012; 67:327-35.

28. Laffey JG, Boylan JF, Cheng DC. The systemic inflammatory response to cardiac surgery: implications for the anesthesiologist. Anesthesiology 2002;97:215-52. [CrossRef]

29. O'Dwyer C, Woodson LC, Conroy BP, Lin CY, Deyo DJ, Uchida T, et al. Regional perfusion abnormalities with phenylephrine during normothermic bypass. Ann Thorac Surg 1997;63:728-35. [CrossRef]

30. Kumar M, Killingsworth C, McILwain RB, Timpa JG, Jagadeeswaran R, Namachivayam $\mathrm{K}$, et al. Intestinal Epithelial Apoptosis initiates Gut Mucosal Injury during Extracorporeal Membrane Oxygenation in the Newborn Piglet. Lab Invest 2014; 94:150-60.[CrossRef] 